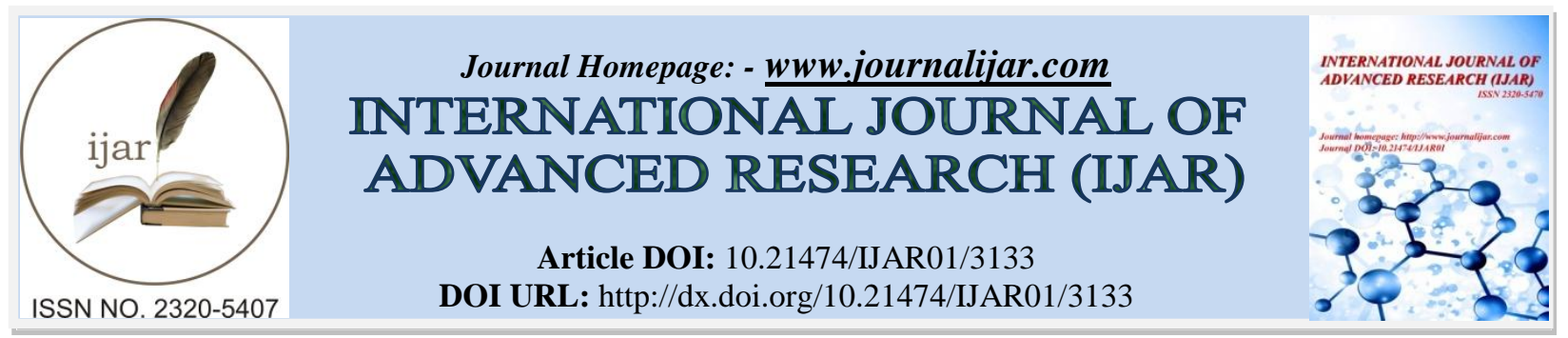

RESEARCH ARTICLE

\title{
PROGNOSTIC SIGNIFICANCE OF SERUM CALCIUM LEVEL IN A SAMPLE OF EGYPTIAN PATIENTS WITH INTRACEREBRAL HEMORRHAGE.
}

\begin{abstract}
Mamun Sarhan, Nahed Shehta, Bothina M. Ramadan and Tamer S. El-Serafy. Department of Neurology, Zagazig University; Egypt.
\end{abstract}

\section{Manuscript Info}

Manuscript History

Received: 10 December 2016

Final Accepted: 05 January 2017

Published: February 2017

Key words:-

Serum calcium, intracerebral

hemorrhage, outcome

\section{Abstract}

Introduction: Calcium $(\mathrm{Ca})$, which is an essential factor for human life, could play a role in pathophysiology of spontaneous intracerebral hemorrhage $(\mathrm{ICH})$. This prospective study was conducted to assess serum $\mathrm{Ca}$ level in a cohort of Egyptian patients with $\mathrm{ICH}$ and searching for a possible association between serum $\mathrm{Ca}$ and both of hematoma volume and short-term outcome after ICH.

Patients and Methods: This study was conducted at intensive care units (ICU) of neurology department, Zagazig University Hospitals, Egypt. We included ninety patients with spontaneous ICH. All patients were subjected to thorough history taking, general and neurological examination. National Institute of Health Stroke Scale (NIHSS) was done on admission to assess stroke severity. Initial Computed Tomography (CT) scans were done for all patients within the first 24 hours of admission to calculate the hematoma volume. Serum Ca level was measured on admission for all patients. Short-term outcome was assessed using the modified Rankin scale after one month of ICH onset.

Results: Among the ninety cases of ICH, (14.4\%) had low serum Ca on admission. Patients with low serum calcium level had a significantly larger initial hematoma volume and higher scores on NIHSS in comparison to ICH patients with normal Ca level. Serum Ca was inversely correlated with hematoma volume $(\mathrm{p}<0.001)$, stroke severity $(\mathrm{P}<0.001)$ and stroke outcome according to modified Rankin scale.

Conclusion: low serum $\mathrm{Ca}$ level on admission was associated with large initial hematoma volume and unfavorable outcome in patients with spontaneous ICH.

Copy Right, IJAR, 2017,. All rights reserved.

\section{Introduction:-}

Spontaneous intracerebral hemorrhage $(\mathrm{ICH})$ is considered as the most catastrophic stroke, it accounts for approximately $15-20 \%$ of all cerebrovascular strokes ${ }^{1-2}$. Being associated with higher morbidity and mortality, it is considered a major public health problem and needs an effective therapy ${ }^{2}$. Accurate identification of predictors of outcome may help optimal beginning time for immediate intervention and management, which might influence early mortality following ICH. Earlier studies have investigated great associations between clinical, laboratory and 
radiographic factors on one hand and outcomes in patients with ICH on the other hand ${ }^{3-4}$. One of these factors is the initial Large hematoma volume which could be considered as an independent predictor of mortality and poor neurologic outcome after acute $\mathrm{ICH}^{5}$.

Serum calcium (Ca) is an essential factor for human life, it plays a role in the pathophysiology of cerebral ischemia and influences the molecular pathways of ischaemic neuronal death ${ }^{6-7}$. Previous researchers ${ }^{6-8}$ had reported an association between serum Ca level and ischemic strokes as it was observed that a high serum Ca level was associated with a small infract size and less severe ischemic stroke ${ }^{7}$. In addition, Appel et al., ${ }^{9}$ observed that ischemic stroke patients with high ca level had a favorable outcome in comparison to those with low Ca level. Moreover, others demonstrated in a previous study that individuals with high dietary Ca intake had a reduced stroke risk $^{10}$.

Data from experimental studies showed an association between $\mathrm{Ca}$ levels and changes in bleeding and clotting time $^{11-12}$, thus it was suggested that Ca could play a role in haemostasis in the setting of acute ICH ${ }^{13}$. Recently, few data were published on the relation between serum Ca level and the initial hematoma volume ${ }^{14}$ as well as outcomes after $\mathrm{ICH}^{13-15}$. However, the underlying mechanisms are poorly understood ${ }^{14}$.

The aim of the current study was to assess serum Ca level in patients with primary ICH and searching for a possible association between baseline $\mathrm{Ca}$ level and both of hematoma volume and short-term clinical outcome.

\section{Patients and Methods:-}

This study was conducted on 90 patients with primary intracerebral haemorrhage (ICH) who were admitted in Intensive Care Unit (ICU) and stroke Unit of Neurology Department, Zagazig University Hospitals during the period from July 2015 till April 2016. Patients were selected according to the following criteria: patients with ICH who were admitted within 24 hours of symptoms onset. Intracerebral haemorrhage was defined as a new and acute ( $<24$ hours) neurological deficit with compatible brain imaging showing the presence of intracerebral bleeding ${ }^{16}$. Patients with ICH secondary to trauma, tumor, vascular malformation, current use of anticoagulation and those with haemorragic transformation Excluded from the study.

All patients were subjected to the following: detailed medical and neurological history taking from either patients or relatives with stressing on stroke risk factors, complete general and neurological examination with assessing stroke severity using National Institute of Health Stroke Scale (NIHSS) ${ }^{17}$ which was done on admission. Brain Computed Tomography (CT) scans was done within the first 24 hours of symptom onset to diagnose ICH and to calculate the volume of intracerebral hematoma. Hematoma volume was measured on the initial head CT scan with the use of the $\mathrm{ABC} / 2$ equation ${ }^{18}$, in which $\mathrm{A}$ is the greatest diameter on the largest hemorrhage slice, $\mathrm{B}$ is the diameter perpendicular to $\mathrm{A}$, and $\mathrm{C}$ is the approximate number of slices with hemorrhage multiplied by the slice thickness .

Laboratory investigations including Complete Bood Count, blood glucose level, liver and kidney functions, lipid profile. Assessment of total serum calcium level was done on admission for all patients from venous blood samples. Low calcium level was considered when total serum calcium was less than $8.6 \mathrm{mg} / \mathrm{dl}$ according to the reference range of our laboratory. Informed consent from patients or their relatives about the study were obtained. This study was approved by the local ethical committee of Zagazig university hospitals.

Short term outcome was evaluated for the surviving patients after one month from ICH onset using modified Rankin scale ${ }^{19}$ which estimates the patient disability with a score ranging from 0 to 6 patients with a score of $0-2$ had a favorable outcome. Those with a score of more than 2 considered unfavorable outcome .

\section{Statistical Analysis:-}

We used SPSS version 20 software package ${ }^{20}$ for data analysis. Quantitative variables were expressed as mean \pm $\mathrm{SD}$ whereas qualitative variables were expressed as number and percentage. Comparison between groups was done using Chi-square test ( $\chi 2$ test) or Fisher extract for categorical variables and Student t-test for continuous variables. Correlations between continuous variables were assessed by Spearman correlation coefficient. P-value< 0.05 was considered significant. 


\section{Results:-}

A total of ninety patients with a mean age of $68.11 \pm 10.79$ years were included in this study, Fifty - six were men and thirty-four were women. According to the serum Ca level, we had two main groups: a group of ICH patients with low calcium level $<8.6 \mathrm{mg} / \mathrm{dl}$ which included 13 patients $(14.4 \%)$. The other group consisted of patients with Ca level $\geq 8.6 \mathrm{mg} \backslash \mathrm{dl}$. Baseline demographic and clinical characteristics according to Ca levels were listed in Table 1. There was no significant difference between those with low and normal calcium level groups as regard sex, age or stroke risk factors. Mean hematoma volume was significantly higher in hypocalcemic than did the normocalcemic group (68.23 \pm 7.54 versus $24.07 \pm 19.52$ respectively). The mean NIHSS scores at admission was higher in those with low $\mathrm{Ca}$ level than normocalcemic groups denoting that patients with low serum $\mathrm{Ca}$ had a severe stroke and more neurological deficit (27.38 \pm 5.0 versus $12.23 \pm 7.06$ respectively).

There was a significant inverse correlation between serum $\mathrm{Ca}$ levels in all cases of ICH and the following: hematoma volumes $(\mathrm{r}=-0.778, \mathrm{P}<0.001)$; stroke severity $(\mathrm{r}=-0.698, \mathrm{p}<0.001)$; short-term outcome assessed by modified Rankin scale $(\mathrm{r}=-0.707, \mathrm{p}<0.001)$.

Table 1:- Demographic and clinical Characteristics of the studied patients:

\begin{tabular}{|c|c|c|c|}
\hline Variables & $\begin{array}{c}\text { ICH with } \mathrm{Ca}<8.6 \\
(\mathrm{~N}=13)\end{array}$ & $\begin{array}{c}\text { ICH with } \mathrm{Ca} \geq 8.6 \\
(\mathrm{~N}=77)\end{array}$ & P-value \\
\hline Age & $67.85 \pm 10.52$ & $68.37 \pm 11.06$ & 0.87 \\
\hline $\operatorname{Sex}(M \backslash f)$ & $7 / 6$ & $41 / 36$ & 0.96 \\
\hline \multicolumn{4}{|l|}{ Risk factor: } \\
\hline HPN, $n$ & 8 & 30 & 0.12 \\
\hline $\mathrm{DM}, \mathrm{n}$ & 6 & 26 & 0.38 \\
\hline Dyslipidemia, $\mathrm{n}$ & 6 & 30 & 0.62 \\
\hline Smoking, $\mathrm{n}$ & 5 & 28 & 0.33 \\
\hline \multicolumn{4}{|l|}{ At admission : } \\
\hline Systolic B1 .p & $170.43 \pm 20.12$ & $168.79 \pm 23.54$ & 0.86 \\
\hline Diastolic B1. P & $95.78 \pm 10.51$ & $94.95 \pm 11.64$ & 0.79 \\
\hline \multicolumn{4}{|l|}{ Laboratory findings: } \\
\hline TG & $130.80 \pm 41.28$ & $122.40 \pm 36.57$ & 0.49 \\
\hline T. cholesterol & $190.66 \pm 33.50$ & $194.34 \pm 27.40$ & 0.71 \\
\hline HDL & $37.64 \pm 11.92$ & $39.15 \pm 12.57$ & 0.67 \\
\hline LDL & $117.48 \pm 40.82$ & $123.83 \pm 35.63$ & 0.29 \\
\hline INR & $1.12 \pm 0.8$ & $1.10 \pm 0.57$ & 0.93 \\
\hline
\end{tabular}

ICH: intracerebral hemorrhage; HPN: hypertension; DM: diabetes mellitus; BL.p: blood pressure; TG:

triglycerides; HDL: high density lipoproteins; LDL: low density lipoproteins; INR: international normalized ratio

Table 2:- Relation of serum Ca level with hematoma volume, stroke severity and short-term outcome.

\begin{tabular}{|l|c|c|c|}
\hline \multicolumn{1}{|c|}{ Variables } & $\begin{array}{c}\text { ICH with } \mathrm{Ca}<8.6 \\
(\mathrm{~N}=13)\end{array}$ & $\begin{array}{c}\text { ICH with } \mathrm{Ca} \geq 8.6 \\
(\mathrm{~N}=77)\end{array}$ & $\mathrm{P}$ \\
\hline Hematoma volume: & $68.23 \pm 7.54$ & $24.07 \pm 19.52$ & $0.000^{*}$ \\
\hline Baseline NIHSS: & $27.38 \pm 5.04$ & $12.23 \pm 7.06$ & $0.000^{*}$ \\
\hline m. Rankin scale (mRS): & $4(30.8 \%)$ & $35(45.5 \%)$ & 0.37 \\
Favorable outcome $(<3):$ & $9(69.2 \%)$ & $42(54.5 \%)$ & \\
Poor outcome $(\geq 3):$ & &
\end{tabular}

ICH: intracerebral hemorrhage, Ca: calcium, NIHSS: National Institute of Health Stroke Scale 


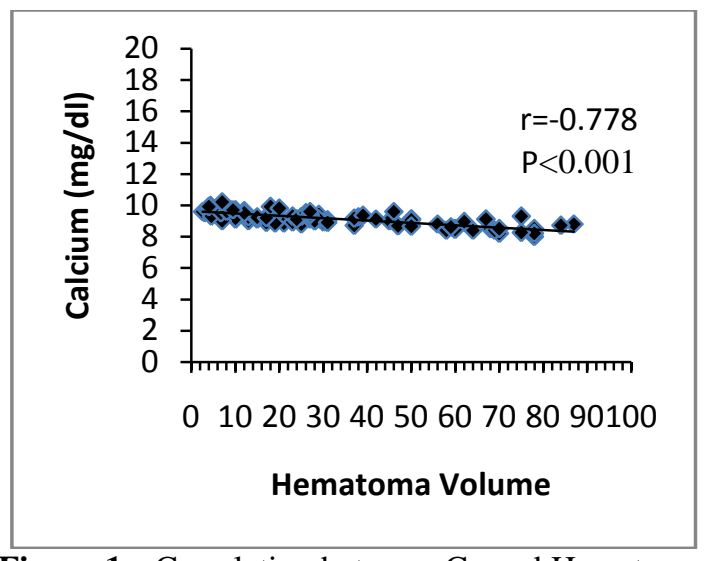

Figure 1:- Correlation between Ca and Hematoma

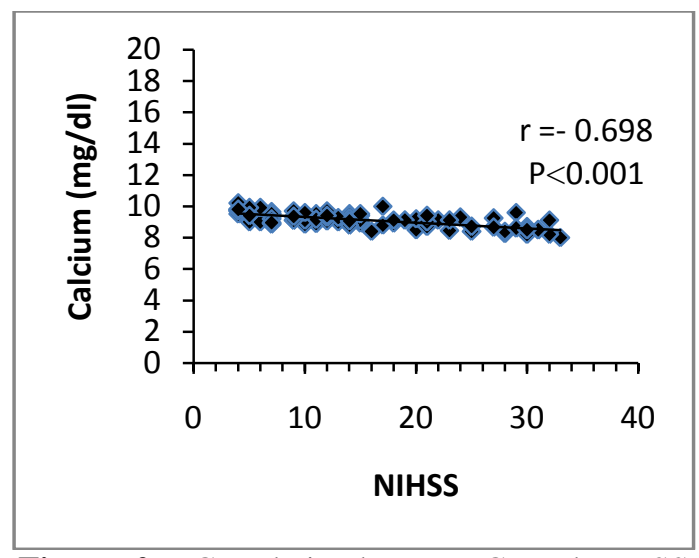

Figure 2:- Correlation between $\mathrm{Ca}$ and NIHSS. volume.

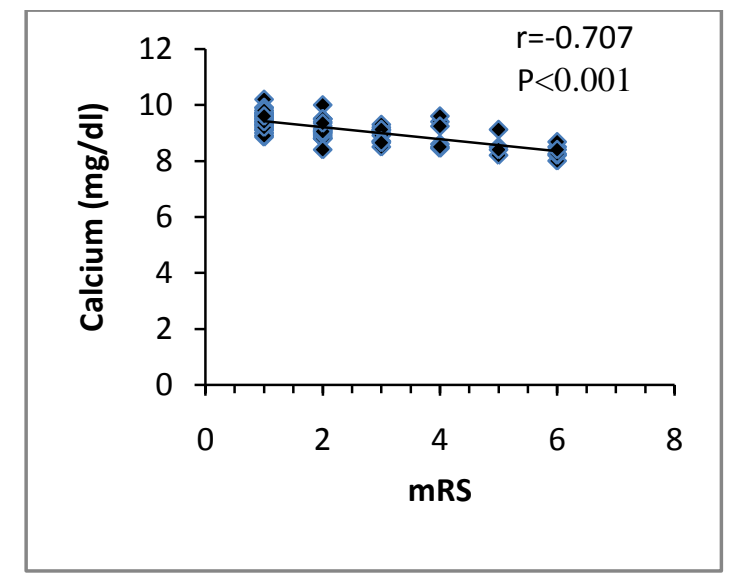

Figure 3:- Correlation between $\mathrm{Ca}$ and $\mathrm{mRS}$ scale.

\section{Discussion:-}

Primary ICH has been reported to be the most devastating form of stroke. It has no proved specific therapy to improve the outcomes according to the results of randomized clinical trials ${ }^{21}$.

Prognostic laboratory biomarkers have the potential to predict endpoints like complications, mortality, or poor functional outcome in the setting of ICH and therefore may enable preventive and therapeutic interventions ${ }^{22}$.

In the current study we investigated the relation between serum $\mathrm{Ca}$ level and both of the initial hematoma volume and the short-term outcome in the setting of ICH, as we included (90) patients who were presented with symptoms and CT evidence of ICH and admitted to ICU units of zagazig university hospitals within 24 hours of symptom onset.

This study demonstrated that patients with low $\mathrm{Ca}$ level had large initial hematoma volume than did those with normal serum Ca. Furthermore, On studying the correlation between serum $\mathrm{Ca}$ in patients with ICH and hematoma volume a significant inverse correlation was observed. Also, the stroke severity was significantly higher in the hypocalcemic than did the normocalcemic group according to the results of admission NIHSS scores. In addition, a negative correlation was observed between serum $\mathrm{Ca}$ level and stroke severity scores as assessed by NIHSS.

These findings were matched with the finding of Morroti et al., ${ }^{14}$, who conducted a cohort study of 2123 consecutive patients with ICH, $10.9 \%$ of their Patients were hypocalcemic and had a higher baseline hematoma volume than did those with normal serum $\mathrm{Ca}$ level. Also they observed a significant inverse correlation between serum $\mathrm{Ca}$ and baseline hematoma volume. 
Similarly, in (2013) Inoue et al., ${ }^{13}$ conducted their study on 273 patients with primary ICH and classified their patients into four quartiles according to serum Ca levels. They reported an association between low serum ca level on admission and initial hematoma volume in patients with acute ICH. Moreover, they demonstrated that the NIHSS scores were higher in patients with the lowest Ca quartile than did patients with the highest $\mathrm{Ca}$ quartile group.

Apart from these studies that concerned with ICH, there are similar observations published recently in support of the association between low $\mathrm{Ca}$ level and the extent of bleeding. Ho et al., ${ }^{23}$ found that hypocalcemia was associated with increased mortality among patients who were bleeding severely. Another recent study conducted by Ho and Yip $^{24}$ demonstrated a decreased clot strength in hypocalcemic patients who were either bleeding or at risk of bleeding and they suggested that hypocalcemia could worsen the existing coagulopathy.

Several mechanisms had been postulated to explain the association between low $\mathrm{Ca}$ and the extent of intracerebral hamatoma. Inuo et al., ${ }^{13}$ stated that $\mathrm{Ca}$ is a cofactor in the coagulation cascade and involved in platelet activation , hence low ca level is associated with large initial haematoma volume through impaired coagulation.

The second postulated mechanism is that $\mathrm{Ca}$ might play a role in vascular reactivity, as stated previously that hypocalcaemia could leads to higher blood pressure . As calcium in its normal levels was reported to induce vascular relaxation of isolated arteries through activation of calcium receptors in the perivascular nerves ${ }^{25}$. The last proposed mechanism that explain the association between $\mathrm{Ca}$ and $\mathrm{ICH}$ is that lower serum $\mathrm{Ca}$ could reflect a poor liver function as stated by Inuo et . ${ }^{13}$ who observed in their study a higher percentage of ICH patients having poor liver function and hence poor coagulation resulting in the large hematoma volume.

The relation between serum $\mathrm{Ca}$ and stroke outcomes has been studied previously. It was observed that poor outcome in patients with ischemic stroke was related to lower serum calcium on admission ${ }^{6,8,26}$. Moreover, previously D' Erasmo and colleagues ${ }^{27}$ recorded that low serum $\mathrm{Ca}$ was associated with in-hospital mortality among ischemic stroke patients. Furthermore, data from large epidemiological studies ${ }^{10,28}$ had showed that dietary calcium intake was associated with reduced mortality after stroke.

In the current study we assessed the relation between serum ca and short term outcome after one month of stroke onset using modified Rankin scale, we observed that ICH patients who had a low serum $\mathrm{Ca}$ developed a high scores on m.Rankin scale than did those with normal Ca levels. In addition, an adverse correlation was observed between serum $\mathrm{Ca}$ and modified Rankin scores that means patients with higher serum ca at admission had an excellent outcome after ICH.

This result was matching with a study conducted by You et al. ${ }^{15}$ in (2015). They studied a total of 365 patients with primary ICH and assessed the relation between serum $\mathrm{Ca}$ on one hand and short and long-term outcomes on the other hand. They demonstrated that elevated admission serum $\mathrm{Ca}$ level was positively associated with excellent outcome at both discharge and three months after acute ICH.

In line with the current study, Appel and colleagues ${ }^{9}$ had studied 784 consecutive patients with acute strokes including both ischemic and hemorrhagic types. They demonstrated an association between the baseline serum $\mathrm{Ca}$ level and stroke severity and outcome. In addition, they concluded that serum calcium concentrations could be considered as a marker of mortality in acute stroke patients.

The exact mechanisms that lie beneath the association between high serum $\mathrm{Ca}$ and favorable outcomes are unclear although several hypotheses were suggested. Foley et al., ${ }^{7}$ suggested that in the setting of neuronal injury that resulted during cerebral ischemia, a more calcium is shifted to the brain from the blood hence Ca could play a neuroprotective role by enhancing the antiapoptotic pathways. Any subtle increase in $\mathrm{Ca}$ in the extracellular space leads to activation of intracellular second messenger and initiation of the antiapoptotic mechanisms ${ }^{29}$. Previously, it was reported that moderate increase in $\mathrm{Ca}$ may promote the cell survival programs and potentiates resistance to hypoxia or ischemia through activated protein kinase B and mitogen activated protein kinase extracellular regulated protein pathways ${ }^{30-31}$. Another suggested hypothesis was that $\mathrm{Ca}$ had a role in maintaining the blood brain barrier integrity, as reported previously that low calcium levels disturb adhesion and tight junctions ${ }^{32-33}$ resulting in cerebral edema which in turn leads to poor outcomes ${ }^{34-35}$. 


\section{Conclusion:-}

Low Serum Calcium level in the setting of ICH is an indicator of large hematoma volume. There is an relationship between serum Ca level and short-term outcome in patients with $\mathrm{ICH}$, hence serum Ca level could be one of the laboratory biomarkers of prognostic significance in the setting of primary $\mathrm{ICH}$. Thus this study recommends starting modifying calcium levels of patients with ICH arriving in the emergency department as soon as possible to improve the clinical outcome.

\section{References:-}

1. Van Asch CJ, Luitse MJ, Rinkel GJ, Van Der Tweel I, Algra A, Klijn CJ. Incidence, case fatality, and functional outcome of intracerebral haemorrhage over time, according to age, sex, and ethnic origin: a systematic review and meta-analysis. Lancet Neurol 2010; 9: 167- 176.

2. Brouwers H. B and Greenberg M .S. Hematoma Expansion following Acute Intracerebral Hemorrhage. Cerebrovasc Dis 2013;35:195-201.

3. Ruiz-Sandoval J.L., Chiquete E., Romero-Vargas S., Padilla-Martínez J.J., and González-Cornejo S. Grading Scale for Prediction of Outcome in Primary Intracerebral Hemorrhages. Stroke J. 2007 ; 38:1641-44.

4. Mansouri B., Heidari K., Asadollahi S., Nazari M., Assarzadegan F., and Amini A. Mortality and functional disability after spontaneous intracranial hemorrhage: the predictive impact of overall admission factors. Neurol Sci. J. 2013; 34:1933-9.

5. Jordan LC, Kleinman JT, Hillis AE. Intracerebral hemorrhage volume predicts poor neurologic outcome in children. Stroke 2009; 40:1666-1671.

6. Ovbiagele B, Starkman S, Teal P. Serum calcium as prognosticator in ischemic stroke. Stroke 2008; 39: 22312236.

7. Foley RN, Collins AJ, Ishani A. Calcium-phosphate levels and cardiovascular disease in community-dwelling adults: the Atherosclerosis Risk in Communities (ARIC) Study. Am Heart J 2008; 156: 556-563.

8. Ovbiagele B, Liebeskind DS, Starkman S. Are elevated admission calcium levels associated with better outcomes after ischemic stroke? Neurology 2006; 67:170-173.

9. Appel SA, Molshatzki N, Schwammenthal Y. Serum calcium levels and long-term mortality in patients with acute stroke. Cerebrovasc Dis 2011; 31:93-99.

10. Iso H, Stampfer MJ, Manson JE. Prospective study of calcium, potassium, and magnesium intake and risk of stroke in women. Stroke 1999; 30:1772-1779.

11. Fukuda T, Nakashima Y, Harada M, Toyoshima S, Koshitani O, Kawaguchi Y. Effect of whole blood clotting time in rats with ionized hypocalcemia induced by rapid intravenous citrate infusion. J Toxicol Sci. 2006; 31:229-234.

12. Fujita Y, Doi K, Harada D, Kamikawa S. Modulation of physiological haemostasis by irrigation solution: comparison of various irrigation solutions using a mouse brain surface bleeding model. J Neurosurg. 2010; 112:824-828.

13. Inoue Y, Miyashita F, Toyoda K, Minematsu K. Low Serum Calcium Levels Contribute to Larger Hematoma Volume in Acute Intracerebral Hemorrhage. Stroke. 2013; 44: 2004-2006.

14. Morotti A, Charidimou A, Phuah C-L, Jessel M J, Schwab K,. Ayres AM. Association between serum calcium level and extent of bleeding in patients with intracerebral hemorrhage: JAMA Neurol. 2016; 73(11):1285-1290.

15. You, S, Han Q, Xu J, Zhong C, Zhang Y, Liu H. Serum Calcium and Phosphate Levels and Short- and Long-Term Outcomes in Acute Intracerebral Hemorrhage Patients. Journal of Stroke and Cerebrovascular Diseases. 2015: doi.org/10.1016/j.jstrokecerebrovasdis..12.023

16. Falcone Gj, Biffi A, Brouwers H. B, Anderson C D, Battey T W, Ayres A M. Predictors of Hematoma Volume in Deep and Lobar Supratentorial Intracerebral Hemorrhage. JAMA Neurol.2013; 70: 988-94.

17. Kasner SE (): Clinical interpretation and use of stroke scales. The Lancet Neurology. 2006; 5(7): 603-612.

18. Divani AA, Majidi S, Luo X, Souslian FG, Zhang J, Abosch A. The ABCs of accurate volumetric measurement of cerebral hematoma.Stroke. 2011; 42: 1569-1574.

19. Weisscher N., Vermeulen M., Roos Y., De Haan R.: What should bedefined as good outcome in stroke trials; a modified Rankin score of 0-1 or 0 2?.Neurol J. 2008; 255:867-74.

20. IBM Corp. Released 2010. IBM SPSS Statistics for Windows, Version 20. Armonk, NY: IBM Corp; 2010

21. Brouwers H.B., Chang Y., Falcone G.J. Cai X., Ayres A.M., Battey T.W., Vashkevich A. Predicting hematoma expansion after primary intracerebral hemorrhage. JAMA neurology. 2014; 71:158-64. 
22. Senn R., Elkind M. S., Montaner J., Christ-Crain M., Katan M. Potential Role of Blood Biomarkers in the Management of Nontraumatic Intracerebral Hemorrhage. J Cerebrovasc Dis. 201 4; 38:395-409.

23. Ho KM, Leonard AD. Concentration-dependent effect of hypocalcaemia on mortality of patients with critical bleeding requiring massive transfusion: a cohort study. Anaesth Intensive Care. 2011;39(1): 46-54.

24. Ho KM, Yip CB. Concentration-dependent effect of hypocalcaemia on in vitro clot strength in patients at risk of bleeding: a retrospective cohort study. Transfus Med. 2016; 26(1):57-62.

25. Bukoski RD, Bian K, Wang Y, Mupanomunda M. Perivascular sensory nerve Ca2+ receptor and Ca2+induced relaxation of isolated arteries. Hypertension. 1997; 30:1431-1439.

26. Buck BH, Liebeskind DS, Saver JL. Association of higher serum calcium levels with smaller infarct volumes in acute ischemic stroke. Arch Neurol 2007; 64:1287- 1291.

27. D’Erasmo E, Pisani D, Romagnoli S. Acute serum calcium changes in transient ischemic attack and cerebral infarction. J Med 1998; 29:331-337.

28. Umesawa M, Iso H, Date C. Dietary intake of calcium in relation to mortality from cardiovascular disease: the JACC Study. Stroke 2006; 37:20-26.

29. Lin KI, Chattopadhyay N, Bai M. Elevated extracellular calcium can prevent apoptosis via the calcium-sensing receptor. Biochem Biophys Res Commu 1998; 249:325-331.

30. Fahlman CS, Bickler PE, Sullivan B. Activation of the neuroprotective ERK signaling pathway by fructose1,6-bisphosphate during hypoxia involves intracellular Ca2+ and phospholipase C. Brain Res. 2002; 958:4351

31. Cheng A, Wang S, Yang D. Calmodulin mediates brain-derived neurotrophic factor cell survival signaling upstream of Akt kinase in embryonic neocortical neurons. J Biol Chem 2003; 278:7591-7599.

32. Alexander JS, Blaschuk OW, Haselton FR. An N-cadherin-like protein contributes to solute barrier maintenance in cultured endothelium. J Cell Physiol 1993; 156:610-618.

33. Pokutta S, Herrenknecht K, Kemler R. Conformational changes of the recombinant extracellular domain of Ecadherin upon calcium binding. Eur J Biochem 1994; 223:1019-1026.

34. Ma TY, Tran D, Hoa N. Mechanism of extracellularcalcium regulation of intestinal epithelial tight junctionpermeability: role of cytoskeletal involvement. MicroscRes Tech 2000;51:156-168.

35. Brown RC, Davis TP. Calcium modulation of adherens and tight junction: a potential mechanism for bloodbrain barrier disruption after stroke. Stroke 2002; 33:1706- 1711 